\title{
REPRESENTAÇÕES SOCIAIS DE ALUNOS SOBRE CURSOS EAD: UMA ANÁLISE DOS SUJEITOS E DAS ESCOLHAS
}

\author{
Antônia Lucineire de Almeida ${ }^{1}$ \\ Iraelza de Fátima Coelho Monteiro ${ }^{2}$ \\ Patrícia Ortiz Monteiro ${ }^{3}$ \\ Edna Maria Querido de Oliveira Chamon ${ }^{4}$
}

Resumo: Este trabalho pressupõe-se apresentar as Representações Sociais de alunos de cursos em EAD sobre sua escolha. Tem-se como objetivos conhecer as Representações Sociais de alunos matriculados em cursos de Ensino Superior - Licenciatura e Tecnológicos -, identificar o público que opta por um curso EAD e investigar os motivos das escolhas dos alunos. Trata-se de uma pesquisa à luz da Teoria das Representações Sociais, exploratória e com abordagem quanti-quali. Como instrumento de pesquisa utilizou-se questionário semiestruturado, aplicado a 181 alunos de cursos $E A D$, de uma Universidade do Vale do Paraíba. Como resultado obteve-se, nos dados sócios demográficos que, as mulheres são maioria nos cursos EAD e que os sujeitos que a compõe são pessoas que atuam no mercado de trabalho, tem família constituída e optam pela EAD por ser uma modalidade mais flexível em termos de tempo e lugar e ainda possibilitam a realização de um curso superior. Nota-se que as representações permeiam as escolhas dos cursos no que tange à escolha pessoal, a realização profissional e a profissionalização.

Palavras-chave: Representações Sociais; Educação a Distância; Público EAD.

\footnotetext{
${ }^{1}$ Mestrando em Desenvolvimento Humano/Universidade de Taubaté, Brasil. E-mail: antonialucineire74@gmail.com.

2 Mestrando em Desenvolvimento Humano/Universidade de Taubaté, Brasil. E-mail:profiraelza@gmail.com.

${ }^{3}$ Mestrando em Desenvolvimento Humano/Universidade de Taubaté, Brasil. E-mail: patrícia@epts.com.br.

${ }^{4}$ Mestrado em Desenvolvimento Humano/ Universidade de Taubaté, Brasil. E-mail: edna.chamon@gmail.com.
} 